\title{
UN LUGAR DONDE VIVIR. LAS LUCHAS MIGRANTES POR EL ACCESO AL ESPACIO URBANO EN LA CIUDAD DE CÓRDOBA (ARGENTINA)
}

\author{
A place to live. The fight of migrants to gain access \\ to the urban spaces of the city of Cordoba (Argentina)
}

María Victoria Perissinotti ${ }^{1}$

\begin{abstract}
Resumen. Basado en un trabajo etnográfico realizado en la ciudad de Córdoba (Argentina), este artículo busca contribuir al creciente número de trabajos que se preguntan por el agenciamiento político de los migrantes. Específicamente, se propone analizar los modos en que las prácticas políticas de un grupo de mujeres peruanas que habitan en la periferia urbana de dicha ciudad, se relacionan y articulan con los procesos migratorios en los cuales se enmarca su arribo a Córdoba. Para ello, se sumerge en un conjunto de experiencias que buscan poner en primer plano los avatares de las luchas que llevan adelante. Muestra entonces la potencialidad de politizar analíticamente la migración, más allá de los momentos específicos en los cuales los migrantes reivindican derechos socialmente considerados como de migrantes.
\end{abstract}

Palabras clave: migraciones, prácticas políticas, espacio urbano, etnografía.

\begin{abstract}
Based on an ethnographic field work made in Córdoba city (Argentina), this article seeks to contribute with the growing number of research that is wondering about migrant's political agency. The main aim of the article is to analyze the ways in which the political practices of a group of Peruvian women living in the periphery of the city are related to the migratory processes that place them in Córdoba. To that purpose, the paper explores different struggles that are in the foreground of their experiences in the city. Hence, it shows the potentiality of analytically politicizing the migration phenomena, even beyond the specific moments in which migrants claim for rights socially conceived as migrant's rights.
\end{abstract}

Keywords: migration, political practices, urban space, ethnography.

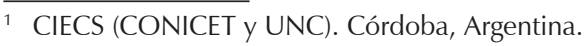




\section{Introducción}

Este artículo busca contribuir al creciente número de trabajos que, desde diferentes espacios geográficos y variadas perspectivas teóricas, vienen preguntándose por el agenciamiento político de migrantes. Específicamente, se propone analizar los modos en que las prácticas políticas de un grupo de mujeres peruanas que habitan en la periferia urbana de la ciudad de Córdoba (Argentina) se relacionan y articulan con los procesos migratorios en los cuales se enmarca su arribo a dicha ciudad. Para ello, busca comprender las experiencias de politización a partir de entender un aspecto clave de la subjetividad migrante como es la permanencia en el lugar de destino.

Las experiencias políticas desarrolladas por varones y mujeres migrantes remiten a una problemática que ha recibido creciente atención en los últimos años. Así, se incrementaron los trabajos que desde la sociología de las migraciones se preocupan por indagar en el accionar de los migrantes en tanto "sujetos que expresan resistencia y prácticas conflictivas innovadoras" ${ }^{2}$. Estos estudios, en sus diferentes vertientes, convergen en señalar la importancia de estudiar la capacidad de agencia política de los migrantes, en tanto se trata de personas que "pueden y suelen ser en muchos casos sujetos políticos activos"3. Sin pretensiones de exhaustividad, podríamos agrupar las preocupaciones de estas investigaciones en torno a tres grandes intereses. En primer lugar, aquellas que se preguntan por el derecho al voto de los migrantes tanto en el país de origen como en el de destino ${ }^{4}$. En segundo lugar, investigaciones que indagan en las prácticas de las organizaciones de migrantes 5 . Por último aquellos estudios que, desde la categoría de "ciudadanía", analizan reclamos específicos vinculados al acceso a derechos jurídicos, sociales y políticos en los países de destino ${ }^{6}$.

En términos generales, aquello que estos trabajos señalan es que, en procesos concretos de reclamos y demandas al Estado, los migrantes estarían

\footnotetext{
MEZZADRA, Sandro. Derecho de fuga: Migraciones, ciudadanía y globalización, p. 147.

ESCRIVÁ, Ángeles. Conclusiones, p. 332.

4 Cf. ALARCÓN, Gilmer. Derechos políticos de los latinoamericanos en España y participación en elecciones locales, p. 45-64; ESCRIVÁ, Ángeles. La doble participación política de los peruanos en España durante la primavera de 2011, p. 7-33; MORAES, Natalia. El voto que el alma no pronuncia: un análisis de las movilizaciones y los discursos sobre el derecho al voto de los uruguayos en el exterior, p. 103-123; LAFLEUR, Jean-Michel. La participación política de los emigrantes bolivianos en las elecciones de su país de origen.

5 Cf. BOLZMAN, Claudio. Chilenos en Suiza: de una comunidad política a una comunidad de residentes, p. 183-202; GRIMSON, Alejandro, JELIN, Elizabeth. Migraciones regionales hacia la Argentina: Diferencia, desigualdad y derechos.

6 Cf. CHERUBINI, Daniela. Llegar a ser ciudadanas. Ciudadanía y prácticas participativas de las mujeres migrantes en Andalucía; ISIN, Engin. Citizenship in flux. The figure of the activist citizen, p. 367-388; MC NEVIN, Ann. Contesting citizenship: Irregular migrants and new frontiers of the political; VARELA HUERTA, Amarela. Por el derecho a permanecer y a pertenecer: Una sociología de la lucha de migrantes.
} 
ejerciendo una praxis política y ciudadana que no se encuentra atada a la pertenencia a un Estado-nación. El "derecho a tener derechos" es la fórmula que condensa y nuclea las aproximaciones teórico-políticas de este conjunto de investigaciones. En el presente trabajo busco hacer uso de la potencia analítica y política que esa formulación condensa, inscribiendo los planteos aquí desarrollados en esa línea argumentativa. Ahora bien, el argumento propuesto en este trabajo busca ir más allá de esta premisa. Esto porque, a pesar de la amplitud que dicha perspectiva propone, podría decirse que los trabajos referidos priorizaron las reivindicaciones ligadas con un conjunto de demandas en particular: aquellas asociadas a la regularización de la condición jurídica de los inmigrantes. Dichas investigaciones han analizado organizaciones o movimientos sociales que se erigen y nuclean específicamente desde su identidad migratoria y cuyas acciones se centran en la demanda de derechos "en tanto migrantes". Así pues, la cuestión de la regularización migratoria condensada en la imagen de "los papeles"- aparece en estos trabajos como una cuestión fundamental e ineludible.

En un ejercicio analítico, podemos intuir que la centralidad que adquiere la temática de la regularización en los casos analizados por estos estudios se explica por las fuertes coerciones que pesan sobre los sujetos no-nacionales en los contextos de investigación, en tanto los principales exponentes de esta temática analizan las experiencias de diversos colectivos migratorios radicados en Estados Unidos y la Unión Europea. Además, esta serie de trabajos encuentra un referente empírico crucial en las revueltas de los sans papiers que tuvieron lugar durante el año 1996 en Francia y, posteriormente, en distintos países de Europa ${ }^{7}$. Sin embargo, y más allá de la explicación contextual, dicha centralidad no constituye una cuestión menor, en tanto pone sobre la mesa algunas preguntas fundamentales en relación a las posibilidades, formas y dinámicas de la participación política de migrantes. Entre otras: ¿será que los migrantes sólo pueden participar políticamente en calidad de tales? ¿Será que sólo pueden organizarse como migrantes y para demandar por cuestiones de migrantes? O incluso más: ison solo las cuestiones vinculadas con los papeles y la regularidad jurídica aquellas que constituyen las luchas de migrantes?

Buscando contribuir a la problematización de estos interrogantes, en este artículo pretendo mostrar que las luchas de la migración exceden ampliamente la problemática de la situación jurídica de sus protagonistas. Con este objetivo, indago en otras experiencias que no necesariamente tienen que ver con aquella dimensión: en el caso que aquí analizo no son "los papeles" ni la regularización de su situación jurídica el problema o el disparador de las luchas. Por el

\footnotetext{
7 Cf. MEZZADRA, Sandro. Capitalismo, migraciones y luchas sociales: La mirada de la autonomía,
} p. 162-163. 
contrario, y como veremos a lo largo del trabajo, estas experiencias surgen a partir del activismo de un conjunto de mujeres peruanas que habitan en la periferia urbana de Córdoba y cuyas reivindicaciones pueden condensarse en lo que ellas denominan como su lucha por un lugar donde vivir ${ }^{8}$. Si la mayoría de los estudios que se preguntan por el involucramiento político de migrantes han hecho hincapié en la identidad étnica y migratoria de estos sujetos; el modo en que las mujeres con las que trabajo se involucran políticamente lejos está -por lo menos en apariencia- de centrarse en estas categorías ${ }^{9}$. Partiendo de este problema, en este artículo indago en el proceso a través del cual las mujeres con las que trabajo se han involucrado en un hacer político que no se centra en la cuestión de los papeles ni en su identidad migratoria sino que se vinculan con otro aspecto clave de la subjetividad migrante como es la permanencia. Aquello que se pone en juego en estas prácticas no tiene que ver con la posibilidad de irse o quedarse en el país de destino, sino con el "cómo" quedarse. En ese sentido, la pertenencia de clase se vuelve central, como veremos, para entender las luchas y resistencias en torno a la permanencia.

La principal contribución de este trabajo remite entonces a la posibilidad de politizar analíticamente la migración, más allá del momento específico en que los migrantes salen a la calle como migrantes. Si bien no podré agotar las implicancias que esta apertura conlleva, la posibilidad de poner de manifiesto que los migrantes se involucran políticamente en las sociedades de destino de diversas formas, con distintas estrategias y a partir de múltiples problemáticas, puede resultar productiva para las discusiones que se preguntan por el agenciamiento político de estos sujetos.

Con este objetivo, el artículo se divide en dos partes, orientadas por dos interrogantes específicos. En la primera, busco comprender cómo llega la "activación" política de estas mujeres. En la segunda, intento descifrar cómo, en el desarrollo de su lucha, aparecen cuestiones relacionadas con la migración. Siguiendo a Mezzadra, busco entonces reintroducir analítica y políticamente las luchas de los migrantes en el conjunto "de las más generales transformaciones de la sociedad"10, en vistas a comprender cómo la experiencia social de la movilidad constituye un elemento central en el desarrollo de muchas demandas

8 Las palabras señaladas en itálicas corresponden a categorías nativas recuperadas en el texto fuera de su contexto original de enunciación.

9 Es importante aclarar que, en Argentina, el contexto legal y jurídico que enmarca los procesos migratorios es bastante diferente al europeo o norteamericano. En términos generales -y más allá de las numerosas críticas que puedan realizarse- la Ley 25.871 reconoce la migración como un "derecho humano"; consagra el derecho a la reunificación familiar y establece el derecho irrestricto de los migrantes a acceder a educación y salud pública, con independencia de su condición jurídica. Para un análisis crítico de la Ley, ver: DOMENECH, Eduardo. Las migraciones son como el agua: Hacia la instauración de políticas de "control con rostro humano", p. 119-142.

${ }^{10}$ MEZZADRA, Sandro. Prólogo, p. 18. 
y luchas sociales, "incluso de aquellas que no parecen tener una relación directa con el tema de la migración"11.

En términos teóricos, el artículo se nutre principalmente del enfoque de la autonomía de las migraciones y de la perspectiva interseccional. La autonomía de las migraciones constituye una mirada conceptual que propone "observar los movimientos y conflictos migratorios desde una perspectiva que priorice las prácticas subjetivas, los deseos, las expectativas y los comportamientos de los propios migrantes"12. Al buscar poner de manifiesto "el protagonismo de las mujeres y de los hombres que viven la migración como experiencia social concreta", esta perspectiva brinda importantes herramientas analíticas para pensar en los múltiples modos en que los migrantes luchan y tensionan, a partir de sus experiencias subjetivas, la desigualdad de los procesos migratorios como tales, incluso "mucho más allá del tema de la frontera"13. La perspectiva interseccional, por otro lado, surge como un enfoque teórico-metodológico que busca comprender las relaciones sociales de poder a partir de analizar los modos en que las categorías de género, etnicidad y clase social se articulan en la producción de desigualdades sociales ${ }^{14}$. La apuesta, retomada fuertemente en los estudios sobre migraciones, se centra en discutir la noción de una posición política atada a una única forma de identidad ${ }^{15}$. En este sentido, dicha perspectiva permitirá reflexionar sobre cómo las adscripciones de género, étnicas y de clase van condicionando las trayectorias de las personas con las que trabajo, generando constantemente fronteras internas que las obligan a reclamar derechos fundamentales, como es el de un lugar donde vivir. Al mismo tiempo, al incorporar específicamente la dimensión de género, la interseccionalidad brindará herramientas para comprender por qué son las mujeres quienes participan en la lucha por mejorar sus condiciones habitacionales.

En términos metodológicos, el artículo se basa en un trabajo de campo etnográfico realizado entre 2014 y 2015 en Los Pinos y Sabattini ${ }^{16}$, dos barrios ubicados en la periferia de la ciudad de Córdoba que presentan una importante concentración de migrantes peruanos entre sus habitantes. Como resultado de lo allí realizado, obtuve cuatro entrevistas en profundidad semi-estructuradas a quienes eran reconocidas como referentes de cada uno de los barrios y 69 registros de observación participante con dos grupos de mujeres peruanas que migraron a la ciudad de Córdoba y que participan, como parte de sus experiencias

11 IDEM. Derecho de fuga, p. 17.

${ }^{12}$ IDEM. Capitalismo, migraciones y luchas sociales: La mirada de la autonomía, p. 174.

13 Ibidem, p. 174.

${ }^{14}$ MAGLIANO, María José. Interseccionalidad y migraciones: potencialidades y desafíos, p. 691-712.

${ }^{15}$ ANTHIAS, Floya. Género, etnicidad, clase y migración: interseccionalidad y pertenencia translocalizacional, p. 14-15.

${ }^{16}$ Los nombres propios que aparecen en el trabajo han sido modificados para preservar el anonimato de mis interlocutores. 
cotidianas, en diversos espacios políticos. Más allá de las diferencias entre uno y otro grupo, pueden destacarse como rasgos generales un fuerte activismo territorial ligado al espacio barrial y diversas pero constantes articulaciones con algunos partidos y funcionarios políticos de la sociedad de destino.

\section{Cómo construir territorios habitables: sobre el involucramiento político de mujeres migrantes en Córdoba}

Tomemos la primer pregunta: ¿cómo llega la activación política? Es decir, si no son los papeles aquello que convoca, ni la identidad migratoria lo que nuclea a mis interlocutoras: ¿cuándo y a raíz de qué motivos estas mujeres comenzaron a involucrarse crecientemente en una serie de actividades, relaciones y espacios considerados políticos? La gran mayoría de las mujeres con las que trabajo ${ }^{17}$, comenzaron a organizarse en torno a una problemática particular: la construcción de un espacio habitable en donde vivir. Desde lugares distintos, las experiencias políticas de estas mujeres se encuentran nucleadas en torno a la cuestión de la urbanización de sus barrios. Este es por ejemplo el caso de Grace, quién llegó con su hermana desde Lima el 15 de enero de 1982. Después de mucho tiempo de vivir en una pensión y sin poder acceder a una casa propia durante todos esos años, en el 2009 se enteró que unos compatriotas estaban tomando terrenos en un predio en donde había funcionado un basural a cielo abierto. Como el alquiler era cada vez más costoso, Grace decidió ir a conocer y terminó ocupando un terreno en donde construyó, poco a poco y con ayuda de su marido y su cuñado, su propia casa. En ese barrio, un asentamiento informal en donde las más de 500 familias migrantes que allí viven sufren los problemas de la contaminación y la segregación espacial, Grace se erigió como "líder comunitaria" reconocida por muchos vecinos y enfrentada por otros.

Desde los inicios del barrio, en los que no había más que un puñado de chozas sin agua ni luz, Grace comenzó a organizarse con otros vecinos -muchos provenientes de Perú, pero también de Bolivia y Paraguay- y a convocar reuniones semanales para conseguir diferentes cosas para el barrio. Así, comenzó a asistir regularmente a la Municipalidad, a EPEC ${ }^{18}$, a Aguas Cordobesas ${ }^{19}$ y a distintas reparticiones públicas en reclamo de la instalación de los servicios.

\footnotetext{
17 Vale aclarar que todas ellas poseían, ya al momento de mi trabajo, el permiso de residencia permanente en Argentina y el Documento Nacional de Identidad que la acreditaba. Al igual que ellas, muchos de sus vecinos habían logrado acceder a su documentación a través del "Patria Grande", un programa de regularización documentaria que el Estado nacional desarrolló entre 2006 y 2009 para facilitar los trámites de radicación de extranjeros MERCOSUR viviendo en el país.

${ }^{18}$ Empresa Provincial de Energía Córdoba, es la institución encargada de brindar el servicio de energía eléctrica.

${ }^{19}$ Institución encargada de proveer el servicio de agua corriente.
} 
En 2012, luego de que una fuerte tormenta arrasara con muchas de las viviendas de Los Pinos, Grace se contactó con la trabajadora social del dispensario en busca de ayuda. Con respecto a esto, me comentaba:

Y así fue que nos empezamos a reunir acá en el barrio, empezamos a hacer mucho trabajo social. Nadie nos quería ayudar. La municipalidad nos dio la espalda. Por eso empezamos nosotras solas a hacer todo trabajo comunitario. Al principio éramos dos locas. Y ahora ya somos muchas (Grace, 51 años. Llegó a Córdoba en 1982. Entrevista realizada en noviembre de 2014).

Esas "muchas" son alrededor de 15 mujeres -todas provenientes de Perúque se reúnen una vez por semana con el objetivo de realizar cosas por el barrio. "Mujeres haciendo historia en la comunidad" es el nombre con el que han elegido bautizar su grupo. Así, además de las ya señaladas acciones en pos de la urbanización de su barrio -como las asambleas, cortes de ruta y manifestaciones, entre otras- han realizado desde tareas de apoyo escolar y recreación para los niños, hasta talleres sobre violencia de género.

Como en el caso de Los Pinos, las experiencias que registré en Sabattini, un asentamiento construido sobre terrenos fiscales al este de la ciudad, también surgieron a partir de reclamos vinculados al barrio. $Y$ aquí también son mujeres quienes encabezan la lucha, referenciada en la figura de Marta. Proveniente de Lima, Marta llegó a Córdoba en 2002. Después de varios años de vivir en una pensión, en el 2009 se mudó a Sabattini, el barrio en donde pudo tomar un terreno, gracias a que por ese entonces se estaba conformando como un asentamiento informal. Marta es también, desde 2009, la presidenta de la Comisión Directiva que está trabajando para conseguir la instalación de los servicios básicos para las cerca de 250 familias que allí viven. Como el asentamiento en cuestión se encuentra construido sobre terrenos fiscales propiedad del Estado Nacional, en términos legales se trata de una "ocupación". Es decir, no tienen propiedad sobre el suelo que habitan y su presencia allí es irregular. Por este motivo, hasta hace poco tiempo, los habitantes de Sabattini no poseían acceso a ninguno de los servicios básicos -agua corriente, energía eléctrica y gas natural-. Esto llevó a que Marta y sus vecinos iniciaran un peloteo por variadas instituciones del gobierno municipal y provincial, en búsqueda de conseguir las autorizaciones necesarias para que los entes reguladores de tales servicios los instalasen. A lo largo de este recorrido -por demás arduo, aunque también satisfactorio-, Marta se contactó con diferentes organizaciones y terminó por ser reconocida -tanto por sus vecinos como por los funcionarios estatales- como la referente del barrio.

¿Cómo unimos entonces las experiencias de estas mujeres, tan similares entre sí, incluso si entre ellas no se conocen y si geográficamente se ubican en puntos opuestos de la ciudad? Es el espacio del barrio -y los procesos de su 
conformación- que cobra una relevancia fundamental en este sentido. Tanto Los Pinos como Sabattini son asentamientos ubicados en zonas periféricas de la ciudad de Córdoba y se encuentran construidos sobre terrenos fiscales que, hasta el momento de su ocupación, se hallaban baldíos. Ambos barrios concentran entre sus habitantes una alta población de migrantes, principalmente peruanos. La composición migratoria de estos asentamientos resulta tan llamativa que, como comentaba en una ocasión Marta, es conocido que "los peruanos [han] invadido el barrio" 20 .

El inicio de la construcción de ambos asentamientos se remonta a finales de 2008 y principios del 2009 y el proceso a través del cual se fueron poblando se relaciona estrechamente con las redes sociales que los migrantes logran establecer en destino. Así, la mayoría de los vecinos de estos lugares se enteraron que "se estaban tomando tierras" gracias a sus compañeros de pensiones o de trabajo. Asimismo, la decisión de tomar un terreno en vistas de construir una vivienda se fundamenta en la necesidad de los vecinos, entendida esta como la imposibilidad de acceder al mercado formal. Pero, fundamentalmente, se relaciona con la posibilidad de construir una vivienda que sea propia.

Ahora bien, como indicaba anteriormente, estos espacios se encontraban baldíos hasta el momento de su ocupación. Las plantas, la maleza, los escombros y la basura abundaban cuando los primeros pobladores comenzaron a construir allí sus viviendas. Al mismo tiempo, los servicios básicos eran inexistentes. Estas características hacían que estos espacios fueran percibidos por los migrantes como inhabitables. "Era una desgracia" repetía una y otra vez Mari, una mujer peruana que vive en Los Pinos, cuando le pregunté por su llegada a ese barrio. "Los yuyos eran muy altos, estaba todo lleno de basura -continúa-. Las casitas eran muy chiquitas y todas de cartón. Para mí fue terrible, porque imagínate que uno viene a la Argentina pensando que va a ir a mejorar, y yo estaba acá, que era un río cuando llovía. iY la basura! Fue muy difícil", concluyó (Mari, 45 años. Llegó a Córdoba el 13 de febrero de 2009. Entrevista realizada en febrero de 2014).

A pesar de estas percepciones -compartidas por muchos de mis interlocutores- la imposibilidad de acceder al mercado inmobiliario formal y la falta de políticas públicas que den respuesta a su problemática, hacía que estos espacios sean vistos como una alternativa posible para su instalación. Pero, para poder tornar estos territorios habitables fue necesario un esfuerzo por parte de los sujetos. Ese esfuerzo iba desde arrojar camionadas de tierra limpia para construir allí sus viviendas, hasta la organización de asambleas, comisiones y

${ }^{20}$ Cf. MAGLIANO, María José, PERISSINOTTI, María Victoria, ZENKLUSEN, Denise. Estrategias en torno a las formas de apropiación y organización del espacio en un 'barrio de migrantes' en la ciudad de Córdoba, Argentina, p. 513-539. 
juntas directivas que se presentasen frente a los funcionarios políticos locales para realizar los pedidos y reclamos correspondientes.

Es esa organización, siempre hecha a puro pulmón como contó Mari, lo que llamó mi atención. Pues, es en este proceso de ocupación, apropiación e instalación que estas mujeres migrantes comienzan a desplegar una serie de prácticas políticas tendientes a tornar el territorio habitable. Ellas son quienes han gestionado y conseguido el acceso a los servicios básicos. Ellas son quienes han organizado los trabajos de desmalezamiento y loteo de los terrenos. Y son también ellas quienes, en virtud de estas actividades, han instaurado lazos y relaciones cotidianas con distintos agentes y funcionarios estatales, a quienes interpelaron en la demanda por sus derechos.

Ahora bien, cabe preguntarse: ¿por qué las mujeres? Desde la mirada relacional que propone la perspectiva interseccional, para contestar este interrogante deberíamos preguntarnos también: ¿quiénes son estas mujeres?, ¿cuáles son sus situaciones conyugales y familiares?, ¿dónde están los varones con los que se relacionan?, ¿cómo es el arreglo familiar del tiempo? Como señalé, la mayoría de estas mujeres son migrantes peruanas que arribaron en las últimas décadas a la ciudad de Córdoba. Con algunas excepciones, en general viajaron solas hacia Argentina. Ya acomodadas en destino, quienes tenían familiares viviendo en Perú, organizaron la reagrupación. Otras, conocieron en Córdoba a varones - muchos peruanos- con los cuales formaron familia, de modo que la mayoría son madres de niños en edad escolar. Incluso si muchas de ellas cuentan con estudios terciarios -como maestras o enfermeras- y en algunos casos universitarios, casi la totalidad se desempeña como empleada doméstica. La fuerte racialización del mercado laboral cordobés, así como las trabas burocráticas para el reconocimiento de sus títulos conseguidos en Perú, hicieron que fracasaran una y otra vez en su intento de hacer valer sus estudios para conseguir empleos mejor valorados por ellas ${ }^{21}$. Sus parejas mientras tanto, se desempeñan casi exclusivamente en el ámbito de la construcción, también producto de una fuerte segmentación del mercado laboral a partir de elementos étnicos, raciales y de clase. Mientras que el empleo doméstico con retiro les permite a las mujeres concentrar su jornada laboral en pocas horas, el trabajo en la construcción exige largas jornadas. De hecho, muchos de los varones albañiles viajan a diario hacia zonas fuera del ejido municipal, debiendo irse muy temprano por las mañanas y retornando al caer la tarde.

${ }^{21}$ El trabajo doméstico remunerado constituye una de las salidas laborales casi exclusiva de las mujeres peruanas en Argentina. En un mercado laboral fuertemente etnizado y racializado, es la posibilidad de conseguir un empleo en este sector aquello que orienta en muchos casos la migración de peruanas hacia este país. Cf. COURTIS, Corina, PACECCA, María Inés. Género y trayectoria migratoria: mujeres migrantes y trabajo doméstico en el Área Metropolitana de Buenos Aires, p. 155-185. 
Esta particular configuración del mercado laboral en términos de género, pero también étnicos, raciales y de clase, condiciona las posibilidades de participación de unos y otros. Mientras que, asociados a sus funciones "productivas", los varones se ausentan la mayor parte del día del barrio, las mujeres buscan y pueden permanecer un mayor tiempo allí. Se podría suponer entonces que esta situación se vincula con el hecho de que sean las mujeres quienes activen el "derecho a reclamar derechos" vinculados a lo barrial. Podría decirse incluso que su presencia misma en el barrio es una presencia política. De cualquier manera, esto no invalida los roles que, hacia el interior de las familias, continúan ejerciendo las mujeres. La fuerte división sexual del trabajo hace que las responsabilidades domésticas y de cuidado sigan recayendo sobre las mujeres. De allí la importante presencia de niños durante las reuniones: mientras las adultas discuten sobre cuestiones de su comunidad, es usual observar a grupos de pequeños jugando y corriendo entre las sillas. De allí también que las reuniones se estructuren en los momentos "libres" y se vayan desarrollando en función de eso: comienzan a la siesta, cuando sus hijos ya volvieron de la escuela, y se van "apurando" conforme va cayendo la tarde, puesto que es crucial para ellas tener la comida lista para el arribo de los varones ${ }^{22}$.

Así pues, se puede ver cómo en las trayectorias laborales, tanto de varones como de mujeres, la migración y la informalidad se conjugan generando nuevas y variadas fronteras. Fronteras que podríamos denominar "internas", en tanto se construyen y reconstruyen constantemente en el lugar de destino. Y puesto que la gran mayoría de las mujeres con las que trabajo comenzaron a organizarse en torno a la cuestión de la urbanización de sus barrios, se podría decir que son estas fronteras internas las que buscan sortear en su lucha por la construcción de un espacio habitable en donde vivir.

Ahora bien, si como sostiene Canelo "el cruce entre migración, Estado y espacio urbano fue raramente abordado, aun cuando por separado cada una de las temáticas haya sido foco de importantes estudios" ${ }^{23}$, el desafío sería entonces analizar cuáles son las especificidades que la migración le imprime a estos procesos. Esto nos lleva a la segunda pregunta: ¿cómo, en el desarrollo de su lucha, aparecen cuestiones relacionadas con la migración? Si prestamos atención a las particularidades de los espacios en donde emergen estas experiencias así como a las características de la subjetividad migrante de las personas con las que trabajo, podremos ver que la condición migratoria deja de ser un factor contextual e irrumpe como uno de los factores consustanciales de estas prácticas. Estas reflexiones son el objeto del próximo apartado.

\footnotetext{
${ }^{22}$ Una minuciosa lectura de género requeriría de un análisis mayor, imposible en el marco de este artículo.

${ }^{23}$ CANELO, Brenda. Fronteras internas: Migración y disputas espaciales en la ciudad de Buenos Aires, p. 10.
} 


\section{Acerca de la movilidad como experiencia}

La migración peruana a Córdoba constituye actualmente la corriente más importante de la ciudad, según indica el último censo nacional ${ }^{24}$. Este flujo migratorio comenzó a aumentar durante la década del noventa, por un lado, debido a la crisis económica y política de Perú, y por otro, a causa de la demanda del mercado laboral cordobés que, al requerir mano de obra barata en nichos feminizados, orientó el proceso migratorio en base al trabajo de las mujeres. A principios del siglo XXI se intensificó un flujo de carácter laboral, que presenta "un alto grado de precariedad y vulnerabilidad" y que puede concebirse como migración peruana reciente ${ }^{25}$. En términos generales, se trata de un flujo eminentemente urbano que se concentra en la ciudad capital.

En las llegadas a Córdoba, las redes sociales juegan un papel importante en términos de la distribución geográfica de este flujo, puesto que es a través de ellas que estos migrantes acceden a la ciudad. Tal como sucede en otros espacios, en la ciudad de Córdoba los migrantes encuentran serias limitaciones para conseguir un lugar para habitar. Pero, al mismo tiempo, para estas familias, resulta fundamental construir una casa propia en tanto esto se presenta como un requisito ineludible para consolidar su proyecto migratorio y garantizar su permanencia. Dado que, en general, no cuentan con suficientes recursos para comprar una vivienda, usualmente recurren primero al alquiler. "Sin embargo, este mercado ofrece barreras a la entrada de estos migrantes, incluyendo precios elevados, exigencia de garantías (...) documentos argentinos y certificados de trabajo formalizado" ${ }^{26}$. Sin posibilidades de cumplir con estos requisitos, recurren al abanico de opciones que sus redes migratorias les presentan, enmarcadas dentro de "la informalidad urbana". En Córdoba en particular, esto da como resultado "una creciente concentración y expansión" de la población peruana hacia barrios ubicados en "la zona periférica de la ciudad"; procesos asociados a la precarización que marca fuertemente la trayectoria laboral de este flujo ${ }^{27}$.

Este proceso de "concentración urbana de migrantes, basada en el origen étnico y cultural" forma parte de una tendencia creciente en la Argentina ${ }^{28}$. Aún más, dicha tendencia muestra cómo esta concentración se trasladó

\footnotetext{
${ }^{24}$ INDEC, Censo Nacional de Población, Hogares y Viviendas 2010. Disponible en <http://www. indec.gov.ar/nivel4_default.asp?id_tema_1=2\&id_tema_2=41\&id_tema_3=135>. Acceso el 18.05.2016.

${ }^{25}$ FALCÓN, María del Carmen, BOLOGNA, Eduardo. Migrantes antiguos y recientes: Una perspectiva comparada de la migración peruana a Córdoba, Argentina, p. 242.

${ }^{26}$ VACCOTTI, Luciana. Migraciones, espacio y política: Perspectivas teóricas para el abordaje del rol del Estado en la "lucha por la vivienda" (Ciudad de Buenos Aires, 2001-presente), p. 46.

27 FALCÓN, BOLOGNA, op. cit., p. 240.

28 SASSONE, Susana, MERA, Carolina. Barrios de migrantes en Buenos Aires: Identidad, cultura y cohesión socioterritorial.
} 
específicamente hacia las villas y asentamientos, "territorios de relegación en los que la población de origen migrante (...) se encuentra sobrerrepresentada" 29 . Esto porque, frente a los obstáculos en su proceso de instalación, "las redes sociales que articulan los movimientos migratorios" aparecen como una estrategia posible para acceder a una vivienda ${ }^{30}$. Así, como señalé en el apartado anterior, el modo de asentamiento de migrantes peruanos a la ciudad de Córdoba podría relacionarse con la conformación de barrios con alta presencia de familias migrantes, construidos a través del despliegue de diversas redes sociales, algunas con fuerte carga étnica y nacional ${ }^{31}$.

La importancia de las redes sociales nos lleva a advertir que existen notables similitudes entre las trayectorias de los migrantes regionales y los migrantes internos en las grandes ciudades del país. Así pues, la experiencia de la migración, como configuradora de las formas de acceso a la ciudad, involucra a la vez a nacionales y a extranjeros migrantes. Sin embargo, aún existen ciertas especificidades entre unos y otros en relación a los modos de ocupación de los espacios y a las formas de gestionarlos. "Los argentinos hacemos villas, los peruanos hacen asentamientos" dijo una vez un alto funcionario de hábitat de la Municipalidad de Córdoba, en una conversación con migrantes peruanos e investigadores de dicha ciudad. Más allá de lo anecdótico y de cierta estigmatización que dejó entrever el funcionario con esa clasificación, algo de cierto hay en eso que dijo. Y es que, como se desprende de la observación de los procesos de ocupación tanto de Los Pinos como de Sabattini, existen algunas características que, por su similitud, Ilaman la atención. El proceso de organización previa para la demarcación de los lotes; la organización de los vecinos en comisiones directivas que garanticen el funcionamiento de la ocupación y la gestión sostenida de los representantes para que el Estado provea los servicios básicos, entre otras características de estos procesos, contrastan de manera notable con los modos de ocupación tradicionales de la ciudad de Córdoba en particular y de Argentina en general ${ }^{32}$.

Estas especificidades se relacionan profundamente con las características de los procesos de acceso a la vivienda en Perú, fuertemente vinculados con corrientes de migración interna en ese país. Como señala Hernando de Soto, allí la vivienda informal construida en el marco de tomas de terrenos ha constituido históricamente el modo mayoritario de acceso al espacio urbano para los peruanos de bajos recursos que llegan desde zonas rurales hacia las grandes

\footnotetext{
29 VACCOTTI, op. cit., p. 48.

30 SASSONE, MERA, op. cit.

${ }^{31}$ Cf. MAGLIANO, PERISSINOTTI, ZENKLUSEN, op. cit.

32 Para ahondar en estos procesos, ver: CRAVINO, María Cristina. Las villas de la Ciudad. Mercado e informalidad urbana.
} 
ciudades $^{33}$. En efecto, si bien la mayoría de los vecinos de los barrios en los que realicé trabajo de campo arribaron a Córdoba desde Lima, prácticamente todos ellos habían transitado anteriormente por procesos de movilidad interna. Nacidos en regiones rurales, la mayoría migraron previamente hacia la ciudad de Lima, en donde se ubicaron en "barriadas", zonas periféricas con características muy similares a los asentamientos que aquí construyeron. Este es, entre otros, el caso de Marta, quién apenas llegada a Lima con su familia materna construyó una vivienda informal en San Juan de Lurigancho, una de las barriadas más grandes de dicha ciudad. Así pues, las trayectorias de movilidad interna e internacional aparecen configurando fuertemente las características del acceso a la ciudad también en Córdoba.

Asimismo, las características del proceso de construcción de estos espacios en la ciudad de Córdoba también presentan importantes similitudes con aquellos de Lima. Como sostiene De Soto, estos procesos suelen comenzar con la ocupación de terrenos estatales, principalmente de aquellos que se encuentran baldíos; ocupación producida por -y legitimada en- la necesidad de los "invasores" ${ }^{34}$. Al momento de la toma le sucede el del loteo y desmalezamiento del terreno, en vistas a construir un plano del lugar. Paralelamente, los ocupantes eligen a sus futuros dirigentes, quienes conforman comisiones directivas con el objeto de representar a los vecinos frente al Estado. Son ellos quienes inician las negociaciones en las distintas reparticiones estatales, exigiendo la instalación de los servicios básicos y la infraestructura necesaria.

Fueron estos pasos, seguidos uno por uno, los que pude registrar en mis observaciones y entrevistas tanto en Los Pinos como en Los Artesanos. Es en virtud de este modo de organización que Grace y Marta fueron instituidas como "representantes" de sus barrios -a través de elecciones de directivas- y que comenzaron a peregrinar junto a sus vecinas entre las diferentes reparticiones estatales en búsqueda de garantizar su derecho a un lugar donde vivir. Podemos entender entonces cómo las trayectorias de movilidad y migraciones condensan y se articulan con estas formas de lucha que pude registrar. El objetivo de urbanizar esos espacios - percibidos en un comienzo como inhabitablesresulta fundamental para estos migrantes en tanto los procesos interseccionales que los posicionan en la base de las jerarquías sociales obturan la posibilidad de que puedan acceder a otras alternativas habitacionales. Estas experiencias pueden pensarse entonces dentro del marco más amplio de demandas por el "derecho a la ciudad" que constituye una de las demandas más sobresalientes en el contexto de la reestructuración neoliberal.

\footnotetext{
${ }^{33}$ DE SOTO, Hernando. El otro sendero: La revolución informal.

34 Ibidem.
} 
Así pues, la migración como factor explicativo de las experiencias políticas que aquí describí, no va a emerger sino a condición de dejar de tener como foco la nacionalidad, o más bien, la condición de no-nacionales de los sujetos que la llevan adelante. Por el contrario, allí donde resulta fundamental indagar es justamente en sus experiencias de movilidad. Su involucramiento político se encuentra indisociablemente unido a los procesos de migración en tanto no pueden explicarse sin comprender las múltiples y heterogéneas fronteras -de clase, étnicas y de género- que las atraviesan.

Pero además, la migración constituye un elemento clave de estas experiencias en tanto el involucramiento político de estas mujeres no podría explicarse sin atender a un aspecto clave de la subjetividad migrante como es la permanencia. Los procesos migratorios que enmarcan las llegadas de estas mujeres y sus familias a la ciudad de Córdoba están asociados a una imagen social de progreso: "uno viene a la Argentina pensando que va a ir a mejorar", me comentó Mari, y su comentario se replicó innumerable cantidad de veces a lo largo de mi trabajo de campo. Y es en ese mejorar que la cuestión del "cómo" permanecer en destino aparece con toda su fuerza. Estas mujeres, en su involucramiento político, se han acercado a funcionarios, asociaciones civiles, organizaciones político-partidarias y dependencias estatales no porque se encuentre en juego si deben irse o pueden quedarse habitando esta ciudad, sino en la búsqueda y el reclamo por mejorar las condiciones en las cuales viven. Y eso, sin dudas, rompe con la idea de la "provisionalidad del migrante.

Inspirada en el planteo de Mezzadra, De Genova y Pickles, entiendo entonces que las experiencias que analicé en este trabajo podrían concebirse como "luchas migrantes" 35 por el derecho a la ciudad. O, más precisamente, como luchas de la migración puesto que, aún si no se sostienen en la identidad migratoria de quienes las llevan adelante, sí expresan las múltiples desigualdades que atraviesan y configuran a los migrantes que transitan los espacios urbanos contemporáneos. Esto implica reconocer que la experiencia de la migración define las formas, temporalidades y acciones que adquiere la lucha, incluso si esta no se encuentra vinculada a la condición jurídica de la migración. Así, como sugiere Mezzadra, surge un espacio con una perspectiva diferente y más prometedora que aquella que se enfoca únicamente en las reivindicaciones que realizan los migrantes en calidad de tales. Esta perspectiva nos muestra cómo, ciertas experiencias de lucha, brindan la posibilidad de "construir coaliciones heterogéneas y bases comunes para que se produzca un encuentro entre los migrantes y otros sujetos en conflicto" ${ }^{\prime 36}$.

\footnotetext{
${ }_{35}$ MEZZADRA, Sandro, DE GENOVA, Nicholas, PICKLES, John. New Keywords: Migration and Borders, p. 81.

${ }^{36}$ MEZZADRA, Capitalismo, migraciones..., op. cit., p. 176.
} 


\section{Consideraciones Finales}

Inspirada en una perspectiva teórica y analítica que busca poner de manifiesto "la importancia de las prácticas y reivindicaciones" de los migrantes, incluso de aquellos que "no necesariamente son ciudadanos en términos jurídicos" ${ }^{\prime 37}$, en este trabajo analicé los modos en que las experiencias políticas de un grupo de mujeres peruanas que viven en la periferia urbana de la ciudad de Córdoba se articulan con los procesos migratorios que allí las ubican. Como hemos observado, es en el marco de procesos de urbanización de territorios periféricos para instalarse en la sociedad de destino que estas mujeres comienzan a tejer una trama de lazos políticos que, anclada en el territorio del barrio, las vincula con la política a nivel local.

Tornar habitables espacios baldíos ubicados en las periferias de la ciudad, en vistas a construir un barrio y, en él, una casa propia, se convierte entonces en una lucha que habla de la dimensión política del proceso migratorio ${ }^{38}$, incluso si el sujeto social que la lleva adelante no la reivindica en calidad de migrante. Incluso también si el objeto de sus demandas no remite exclusivamente a la "regularización" de su situación migratoria. Estas consideraciones sólo pueden advertirse si, como señalan Glick Schiller y Çaglar, estamos dispuestos a prescindir de las "lentes étnicas" como primordial entrada al campo migratorio ${ }^{39}$. Sólo así se puede visibilizar que los migrantes tienen múltiples problemáticas, deseos y demandas que no se restringen a su condición de extranjería. Poner de relieve estos procesos permite entonces politizar la migración más allá de aquellas luchas específicas que se expresan a partir de la figura del migrante como sujeto y objeto de reivindicación.

En este sentido, una dimensión que se abre en este trabajo es la posibilidad -y la importancia- de analizar los modos en que los migrantes influyen, intervienen, modifican al Estado y a la política local ${ }^{40}$. Es decir, la importancia de analizar no únicamente cómo el Estado configura e interviene a los migrantes sino también cómo las migraciones lo interpelan y, en esa interpelación, lo transforman. ¿Cómo esos procesos de movilidad están generando relaciones sociales distintas? ¿Cómo van generando nuevos y distintos tipos de sociedades? En tanto la exclusión del ámbito político de los no-nacionales en los estados de destino habla también de una "negación del derecho a la vida"41, estar atentos

\footnotetext{
37 Ibidem, p. 161-162.

${ }^{38}$ Cf. CALDERÓN CHEILUS, Leticia. El Estudio de la dimensión política dentro del proceso migratorio.

${ }^{39}$ GLICK SCHILLER, Nina, ÇAGLAR, Ayse. Locating Migration: Rescaling Cities and Migrants.

${ }^{40}$ Vale la pena agregar, en este sentido, que tras de varios años de lucha, muchas de las mujeres con las que trabajé iniciaron los trámites necesarios para poder participar de las elecciones locales a las que se encuentran habilitadas -municipales y provinciales-.

${ }^{41}$ SAYAD, Abdelmalek. Estado, nación e inmigración, p. 105.
} 
a las formas en que estas mujeres migrantes instituyen de facto su derecho a la participación política, ilumina también formas creativas de resistencia. Y este reconocimiento resulta clave porque son actos cuya significación política resulta crucial en tanto, como advierte Sayad, "pueden tener consecuencias políticas incalculables porque son resuelta y radicalmente (decididamente) innovadores en materia de definición de la personalidad nacional, de la identidad nacional y, en el límite, de la nación"42.

El poner de manifiesto los intersticios a partir de los cuales aquellos sujetos usualmente configurados por el Estado como naturalmente a-políticos "desafían los órdenes instituidos de manera latente" ${ }^{\text {"43, }}$, puede hacernos pensar también en formas otras de construir políticamente nuestras sociedades. Pues, al requerir un "replanteamiento radical de los conceptos políticos establecidos", las luchas de migrantes pueden ayudarnos a pensar en formas nuevas, creativas de hacer sociedad ${ }^{44}$.

Para contribuir con estos procesos de pensamiento, algunas preguntas quedan abiertas en este trabajo: ¿Cómo, en el desarrollo de sus demandas, los migrantes subvierten los órdenes establecidos y naturalizados?; ¿De qué maneras las experiencias de movilidad intervienen en los comportamientos y desarrollos de la lucha?; ¿Cómo esto entra en el panorama local? En fin: ¿Cómo están inventando nuevas formas de hacer política?

\section{Bibliografía}

ALARCÓN, Gilmer. Derechos políticos de los latinoamericanos en España y participación en elecciones locales. In ESCRIVÁ, Ángeles; BERMÚDEZ, Anastasia; MORAES, Natalia (eds.). Migración y participación política: estados, organizaciones y migrantes latinoamericanos en perspectiva local-transnacional. Madrid: CSIC, 2009, p. 45-64.

ANTHIAS, Floya. Género, etnicidad, clase y migración: interseccionalidad y pertenencia translocalizacional. In RODRÍGUEZ, Pilar. Feminismos periféricos. Granada: Alhulia, 2006, p. 49-68.

BOLZMAN, Claudio. Chilenos en Suiza: de una comunidad política a una comunidad de residentes. In ESCRIVÁ, Ángeles; BERMÚDEZ, Anastasia; MORAES Natalia (eds.). Migración y participación política: estados, organizaciones y migrantes latinoamericanos en perspectiva local-transnacional. Madrid: CSIC, 2009, p. 183-202.

CALDERON CHELIUS, Leticia. El Estudio de la dimensión política dentro del proceso migratorio. Sociológica, v. 21, n. 60, enero-abril/2006, p. 43-73.

\footnotetext{
42 Ibidem, p. 113.

${ }^{43}$ VARELA HUERTA, Amarela. Por el derecho a permanecer y a pertenecer. Una sociología de las luchas de migrantes, p. 218.

${ }^{44}$ MEZZADRA, DE GENOVA, PICKLES, op. cit., p. 84.
} 
CANELO, Brenda. Fronteras internas: Migración y disputas espaciales en la ciudad de Buenos Aires. Buenos Aires: Antropofagia, 2013.

CHERUBINI, Daniela. Llegar a ser ciudadanas. Ciudadanía y prácticas participativas de las mujeres migrantes en Andalucía. Granada: EUG, 2010.

COURTIS, Corina; PACECCA, María Inés. Género y trayectoria migratoria: mujeres migrantes y trabajo doméstico en el Área Metropolitana de Buenos Aires. Papeles de Población, v. 16, p. 155-185, 2010.

CRAVINO, María Cristina. Las villas de la Ciudad. Mercado e informalidad urbana. Buenos Aires: Los Polvorines, 2006.

DE SOTO, Hernando. El otro sendero: La revolución informal. Lima: ILD, 1986.

DOMENECH, Eduardo. Las migraciones son como el agua: Hacia la instauración de políticas de "control con rostro humano". Polis, v. 12, n. 35, 2013, p. 119-142.

ESCRIVÁ, Ángeles. Conclusiones. In ESCRIVÁ, Ángeles; BERMúdEZ, Anastasia; MORAES, Natalia (eds.). Migración y participación política: Estados, organizaciones y migrantes latinoamericanos en perspectiva local-transnacional. Madrid: Polyteia, 2009, p. 327-339.

ESCRIVÁ, Ángeles. La doble participación política de los peruanos en España durante la primavera de 2011. Temas de antropología y migración, n. 5, 2013, p. 7-33.

FALCÓN, María del Carmen; BOLOGNA, Eduardo. Migrantes antiguos y recientes: Una perspectiva comparada de la migración peruana a Córdoba, Argentina. Migraciones Internacionales, v. 7, n. 1, 2013, p. 235-266.

GLICK SCHILLER, Nina; ÇAGLAR, Ayse. Locating Migration: Rescaling Cities and Migrants. Ithaca: Cornell University, 2011.

GRIMSON, Alejandro; JELIN, Elizabeth. Migraciones regionales hacia la Argentina: Diferencia, desigualdad y derechos. Buenos Aires: Prometeo, 2006.

ISIN, Engin. Citizenship in flux. The figure of the activist citizen. Subjectivity, v. 29, n. 1, 2009, p. 367-388.

LAFLEUR, Jean-Michel. La participación política de los emigrantes bolivianos en las elecciones de su país de origen. Barcelona: CIDOB, 2012.

MAGLIANO, María José. Interseccionalidad y migraciones: potencialidades y desafíos. Estudos Feministas, v. 23, 2015, p. 691-712.

MAGLIANO, María José; PERISSINOTTI, María Victoria; ZENKLUSEN, Denise. Estrategias en torno a las formas de apropiación y organización del espacio en un 'barrio de migrantes' en la ciudad de Córdoba, Argentina. Estudios Demográficos y Urbanos, v. 29, n. 3, 2014, p. 513-539.

MC NEVIN, Ann. Contesting citizenship: Irregular migrants and new frontiers of the political. New York: CUP, 2011.

MEZZADRA, Sandro. Capitalismo, migraciones y luchas sociales. La mirada de la autonomía. Nueva Sociedad, n. 237, 2012, p. 159-177.

MEZZADRA, Sandro. Derecho de fuga: Migraciones, ciudadanía y globalización. Madrid: Traficantes de Sueños, 2005. 
MEZZADRA, Sandro. Prologo. In VARELA HUERTA, Amarela. Por el derecho a permanecer y a pertenecer: Una sociología de las luchas de migrantes. Madrid: Traficantes de Sueños, 2013.

MEZZADRA, Sandro; DE GENOVA, Nicholas; PICKLES, John. New Keywords: Migration and Borders. Cultural Studies, v. 29, n. 1, 2015, p. 55-87.

MORAES, Natalia. El voto que el alma no pronuncia: un análisis de las movilizaciones y los discursos sobre el derecho al voto de los uruguayos en el exterior. In ESCRIVÁ, Ángeles; BERMÚDEZ, Anastasia; MORAES Natalia (eds.). Migración y participación política: estados, organizaciones y migrantes latinoamericanos en perspectiva local-transnacional. Madrid: CSIC, 2009, p. 103-123.

SAYAD, Abdelmalek. Estado, nación e inmigración. Apuntes de investigación, n. 13, 2008, p. 101-116.

SASSONE, Susana; MERA, Carolina. Barrios de migrantes en Buenos Aires: Identidad, cultura y cohesión socioterritorial. 2007. Disponible en <http://www. reseau-amerique-latine.fr/ceisal-bruxelles/MS-MIG/MS-MIG-1-Sassone_Mera. pdf>. Acceso el 18.05.2016.

VACCOTTI, Luciana. Migraciones, espacio y política: Perspectivas teóricas para el abordaje del rol del Estado en la "lucha por la vivienda" (Ciudad de Buenos Aires, 2001-presente). Estudios Sociales Contemporáneos, v. 11, 2014, p. 38-50.

VARELA HUERTA, Amarela. Por el derecho a permanecer y a pertenecer: Una sociología de las luchas de migrantes. Madrid: Traficantes de Sueños, 2013.

Recibido para publicación en 24.05.2016

Aceptado para publicación en 30.06.2016

Received for publication in May 24 ${ }^{\text {th }}, 2016$

Accepted for publication in June $30^{\text {th }}, 2016$

ISSN impresso 1980-8585

ISSN eletrônico 2237-9843

http://dx.doi.org/10.1590/1980-85852503880004705 